\title{
Prototype Web-based Construction Project Management System
}

\author{
By Swee-Lean Chan ${ }^{1}$ and Nga-Na Leung ${ }^{2}$
}

\begin{abstract}
This paper presents a conceptual model of metadata-based information system for data exchange among Web-based documents for construction project management. The system extracts useful data from the original documents, re-organizes the information according to specific tasks or users, and displays in an integrated web page. The study identifies the comprehensive functional requirements from existing Web-based collaboration systems, and finds out new user requirements by way of a Web-based survey in Singapore. Based on the requirement studies, a prototype model is developed using Unified Modeling Language (UML). Implementation of the conceptual model applies eXtensible Markup Language (XML) technology. Discussions on major concerns about information security, data accessibility, and service quality are given.
\end{abstract}

Key Words: construction project management, information management, conceptual model, Web-based, extensible markup language.

\footnotetext{
${ }^{1}$ Swee-Lean Chan, assistant professor, Department of Building, School of Design and Environment, National University of Singapore, 4 Architecture Drive, Singapore 117566. Fax: (065) 7755502 Tel: (065) 68743419 e-mail: bdgcsl@nus.edu.sg

2 Nga-Na Leung, Ph.D. student, M.E. Rinker, Sr. School of Building Construction, College of Design, Construction and Planning, University of Florida, 331 Architecture Building, Gainesville, FL, 32611-5701. Fax: 1-(352) $3927266 \mathrm{Tel}:$ 1-(352) 2560885 e-mail: nnleung@ufl.edu
} 


\section{INTRODUCTION}

The use of Internet for exchanging information in a work environment has become very important and more so in years to come. Industries that are interdependent and need the involvement of a large number of participants, information and resources tend to benefit from the use of a time-efficient system in communication, retrieval of information, coordination and management work.

The Architectural, Engineering and Construction (AEC) industry, in particular, is characterized by fragmentation (Howard et al., 1989), geographically, and functionally (O'Brien and Al-Soufi, 1993). Geographical fragmentation is caused by the fact that most of the construction projects are based on temporary collaborations of owners, architects, contractors, subcontractors and suppliers. In addition, the locations of the projects and the locations of these partners are usually geographically different.

Functionally, project partners assume different roles (horizontal fragmentation) throughout the entire construction process (vertical fragmentation) (Howard et al., 1989). Due to fragmentation, coordination among various participants throughout the construction process can be a difficult task. The exchanges of information between major players such as project managers, architects, contractors, engineers occur very frequently, in the forms of letters, change orders, drawings, etc. During the construction stage, good communication between project participants on site and those operating from their offices are necessary to ensure no misunderstanding or lacking of information that may cause delay in the completion of projects. 
Internetworking is ideal for the AEC industry since it is cheap, widely available and not too difficult to use. It provides the best communication solution to the fragmented nature of the AEC industry. However, users of Internet face problems such as unstructured, slow and insecure system. The Next Generation Internet (Tolman et al., 2000) promises to overcome the current problems of the Internet.

\section{RESEARCH OBJECTIVES}

This research proposes a conceptual model of Web-based information system for construction project management to facilitate almost instantaneous data exchange among project participants. The system is able to intelligently search for relevant information, extract useful data from the original documents, re-organize the information according to specific tasks and users, and display it in an integrated web page accessible to all the relevant parties in the construction project. The study focuses on project collaboration related functions, such as document exchange and cross-company communications, especially during the construction phase.

\section{WEB-BASED SYSTEMS}

At present, there are three types of Web-based applications for the AEC industry: the feebased project management service; the build-it-yourself solutions; and the web-enabled software (Zhu, 1999). 
The subscription fee project management services are provided by professional IT companies called Application Service Providers (ASPs). Benefits include low implementation cost, few IT expertise needed, easy application upgrade, and simple system requirements. Its limitation is that information is under the control of a third party. Major concerns are information security, data accessibility, and service quality.

The build-it-yourself solutions are suitable for extremely large companies, so that they can tailor the application to best fit their business environment and maintain their own business style. The limitation is obvious that it requires lots of investment, outsourcing and long development cycle.

The last type, web-enabled software, refers to whole-set Web-based software that are bought and maintained by construction companies. This solution is a balance of the former two. It reduces the need for outsourcing, shortens the development cycle and, at the same time, retains the sensitive information under the supervision of in-house technical staff. Limitations are higher initial cost, and greater know-how from staff.

The study recommends the use of fee-based project management service because it facilitates inter-organizational information sharing with affordable price and professional services, which sets the trend for Web-based project management.

$A S P$

The use of the Internet for project collaboration demonstrates great promises as a tool for increased productivity and business performance. Commercial collaboration solutions are 
provided by ASPs. Some of the well-known ASPs in the AEC sector are: AutoDesk (http://www.buzzsaw.com/), BIW (Building Information Warehouse, http://www.biwtech.com/), Bricsnet (http://www.bricsnet.com/), BuildingWork (http://www.buildingwork.com/), Causeway Tech (http://www.causeway-tech.com/), Citadon (http://www.citadon.com/), Constructware (http://www.constructware.com/), Cosential (http://www.cosential.com/), eBuilder (http://www.e-builder.net/), eRoom (http://www.eroom.com/), Meridian (http://www.mps.com/), and Primavera (http://www.primavera.com/) .

By 2002, there are 5 major local ASPs for the Singapore construction market: Cyber-IB (http://www.cyberib.com/), CXHub (http://cxhub.com/), HDBuilder (http://www.hdbuilders.com/), icFox (http://www.icfox.com/), and icx123 (http://www.icx123.com/). Among them, icFox uses Citadon's technology; while CyberIB applies AutoDesk's. The icx123 and CXHub are mainly information provider. They do not provide Web-based project management services. Only HDBuilder has a local technology partner, who develops Web-based solution targeting at the contractors only. The Singapore local portals provide various services in e-commerce, e-project management and information exchange for the local construction industry.

Current commercial web-based management systems are document based, acting as common information repositories for drawings and textual documents. The problems with document-based system lie in many aspects, among which is information overload due to easy-to-get information. Consequently, the crucial information, buried into tons of irrelevant information, is difficult to locate. This causes a waste of time and energy on searching information for decision making. Another problem is data incompatibility. 
Since drawings, calculations, schedules are produced by various specialized software, users have to run applications to view a small part of useful information in each file, and switch between applications to get all fragmented information integrated in their minds.

\section{SYSTEM FEATURES}

In the ISTforCE project (Intelligent Services and Tools for Concurrent Engineering), Cerovsek and Turk (2000) summarized the requirements of a prototype Internet desktop system as: open enough to integrate with other service or tools; customizable to persons and projects; scalable according to construction project size; level of IT infrastructures in the companies; extendable enough to allow project participants to define a tailor made solution that fits each project.

In the GLOBEMEN project (Global Engineering and Manufacturing in Enterprise Networks), Hannus and Kazi (2000) pointed out 5 managerial requirements: standards for external communication; short set-up time and low cost of the common working environment; short learning time of common tools; protection of proprietary knowledge; and support division of responsibilities between team members.

Also in the GLOBEMEN project, Laintinen et al. (2000) highlights the user-centered requirements: users to be able to access and update the required information efficiently based on access rights; be provided with functionality to search for valuable information in various sources quickly and easily; able to synthesize different pieces of information and organize existing knowledge; able to view the well-organized information from 
different perspectives depending on their role in the process; able to accumulate acquired knowledge orderly for future usage; and to generate reports for decision making.

In this study, 7 desirable features of the Web-based construction project management system are identified through a questionnaire survey. 1 They are time and cost consideration; integration; searching for information; knowledge base and intelligence; customizability to persons; customizability to projects; scalability; and others. The next section briefly describes each of these features.

\section{Time and Cost Considerations}

Time and cost considerations are the most straightforward practical issues, yet seldom mentioned by the academy. To remain competitive against numerous upcoming systems with similar features, the system must demonstrate robust functions with affordable price. Short Web-site set-up time and short training time is also of utmost importance. Therefore, there is a trade-off between the effort put into system development and return on investment.

\section{Integration}

Integration is provided throughout project life cycle, with company database, and with project model (A project model contains Object-Oriented CAD, cost, scheduling and other building information of every building element. It is considered the ultimate way to realize data interoperability among different software applications throughout the project

1 The survey was conducted in May 2002 among construction firms in Singapore. Of the 284 invited to participate in the survey, 47 responded and 30 were usable, giving a respond rate of slightly above $10 \%$. 
life cycle); interoperability through AEC industry-wide standards for related information, allowing data sharing between any systems used by any project participant (e.g., ISOSTEP, IAI-IFCs, aecXML, etc.).

Integration is provided with solid modeling, virtual reality, and others. It is present in the software environment where users apply it in their works, so as to reduce rework. The software environment includes the general office software (Word, Spreadsheet), design and project management tools (CAD, scheduling, accounting, invoicing, electronic bid management, task and resource scheduling, and online tracking of plans). For example, the automatic retrieval of metadata resided in Word and Excel files will reduce reentering metadata when uploading files. Integrating contacts and calendars with users' local system will avoid redundant input of contacts and tasks.

\section{Intelligent Search for Information}

Intelligent search for information means quick access to and efficient updating of required information; searching for valuable information in various sources, e.g., the project Web, the Internet, LAN and the local computer; and synthesizing related information in different documents to form a new, complete information for decision making.

\section{Knowledge Base}

Knowledge base means accumulating and organizing acquired knowledge for reuse; supporting knowledge sharing among the team members by providing rapid location and 
retrieval of stored information; and integrating knowledge into team collaboration and decision making, all in an intelligent distributed system environment.

\section{Customizability to Persons}

Customization to persons allows for personalized interfaces; displays information from different perspectives tailored to a user's role or a specific task. Customization provides user familiarized interface to speed up the working process on the user side, and reduce time of training and customer supports on the ASP side.

\section{Customizability to Projects}

Customization to projects means the ASP solution is suitable for all kinds of projects varied in size, type and degree of complexity. Types of features and levels of details can be selectively adopted according to the characteristics and need of the projects, thus to reduce cost and increase usability.

\section{Scalability, Compatibility and Extensibility}

Scalability means the ASP solution is usable for both low and high speed Internet infrastructure. The system should be compatible with data generated by various applications and support heterogeneous data exchange, if possible. Extensibility is to accommodate both existing and developing applications, both in-house and third-party services. 


\section{Others}

Other useful features include: protection of knowledge proprietary, and supporting division of responsibilities among team members. From the perspective of technology, XML support is very important, which means transforming XML compatible documents into document specific XML files and then to generic XML files, e.g. ifcXML, via schema mapping.

\section{CONCEPTUAL MODEL DEVELOPMENT}

The conceptual modeling is depicted in UML within a use case driven approach. A use case describes the functionality performed by the system as a result of a request from an actor (Maciaszek, 2001). A use case driven approach describes the system from the external user's point of view and most suitable for domain knowledge analysis.

There are five packages in the conceptual model, representing five important feature categories: Document Management, Workflow Management, Team Communication, My Project Place, and Administrate Project. Schematic diagrams illustrating the flow of and relationships among the activities are depicted in Figure 1. The next few paragraphs discuss how these packages work.

Setup Project Website 
The use case Setup Project Website is to set up the framework for the website. It defines the standardized templates to manage document and workflow. It also defines the business logics for the system to execute. A template determines the standard and structure of a portfolio. When the user creates a new file, the system obtains certain data from the template. Using a template will quickly create project wide standards and decrease time-consuming data entry. An XML-based standardized template, such as a form for Request For Information (RFI), defines the meaning of each input field, which can be easily interpreted by the system.

\section{Document Management}

The Document Management package serves three main functions: upload file, search file and search topic. In uploading file, metadata of the file, such as author, date and description are required. With metadata, the file can be searched by various criteria. The metadata is saved in XML format.

In the case of file searching, the system can neatly present various search result based on the user's search criteria other than full text search, such as by text in the description of the metadata of the file, or by the category of the file such as draft drawing or shopdrawing. It enhances the quality of file searching by presenting the most targeted file to the user. 
Topic search is an integrated information search and display. It is the most important use case to demonstrate how XML enabled collaboration system differs from others. It searches related information in the project website, and integrates the search result into a single web page. This means user can extract useful pieces of information from all sources in the project website and put them together for analysis and decision-making. It shortens the time needed for information searching and organizing, and allows user to have more time on information analysis and decision-making.

\section{Workflow Management}

In the Workflow Management package, standardized workflow management is realized through information templates and automatic execution of business rules. A workflow consists of several tasks. Tasks are small jobs that the project manager assigns to the project users, such as responding to an RFI, approving a Change Order, etc. When one task finishes, the system automatically brings out the next. When all the tasks are finished, the workflow ends. The benefit of automatic workflow management is to speed up the communication and confirmation of decisions.

\section{Team Communication}

While Workflow Management is a formal way to manage collaboration information, Team Communication can act as less formal discussion. The features of BBS (Bulletin Board System), instant messaging, online conferencing, and emailing provide speedy yet traceable means to record informal discussions and decision-makings. Discussion results can be formally documented in workflow management, such as in minutes of meetings, 
or in the decision-making of approving or rejecting a change order. Team communication thus simplifies the processes of workflow. The inputs in team communication are also saved in XML format, and, therefore, are traceable by using Search Topic.

\section{My Project Place}

My Project Place is a personalized work station. Every user can view his own tasks, and updated information that is relevant to his job. This simplifies the users' environment, and allows the user to concentrate on relevant information. It is possible with XML technology because the system tailors the information to suit the users' need.

In a workflow, each task automatically starts after its precedent event finishes, given that the tasks are assigned to the responsible parties by the Project Manager. This is done through the package of Administrate Project. The preset business rules define the framework of who is responsible to do what by the deadline of when and what if the task is not finished on time. The project manager only needs to fill in the specific items for each collaborative workflow.

The packages described above consist of several top-level use cases. Each use case may consist of several subordinate use cases. Table 1 summarizes the use cases involved in the Web-based RFI process discussed in the following section, as well as the information they provide.

$X M L$ 
To overcome the problem of data incompatibility, implementation of the system employs $\mathrm{XML}$ technology, which is a neutral file format acting as a common language to facilitate data exchange and rapid location of the information. XML is a markup language that handles structured data by separating content from presentation of the information. It is recommended by the $\mathrm{W} 3 \mathrm{C}$ as "the universal format for structured documents and data on the Web" (W3C, 2002a). W3C stands for World Wide Web Consortium, an international organization that develops technical specifications for the web's infrastructure (W3C, 2002b).

In his "malleable frame" system, Zhu (1999) provided a methodology for identifying Document Type Definition (DTD) for construction documents. To date, XML Schemas Definition (XSD), instead of DTD, is applied in the construction industry. IfcXML(IAI, 2001) is one of the internationally recognized XSDs in construction. However, the structure of the ifcXML schema is too complex and elaborated for direct use. Schema mapping between the document schema and the ifcXML schema is necessary. Figure 3 shows the XML document schema of the RFI described in the following section. Schema mapping between the RFI document schema and ifcXML schema involves extension of the ifc model to include schemas such as ReRFI, Responses.

\section{THE PROTYOPE SYSTEM}

The information used in the prototype system is obtained from a real construction project completed in Singapore. In this design-and-build project, the Main Contractor (company $\mathrm{MC}$ ) acts as the project manager and the Architect (company AR) works for MC. The Client (company CL) is a government agency in charge of national MRT (Mass Rapid 
Transit) projects. CL supervises the project, dealing with major decision making, and authorizing changes to the project work. In company MC, YS Liu is the Project Manager $(\mathrm{PM})$, and M Ang is the Quantity Surveyor (QS). K Foo is the Qualified Person (QP) and chief architect in company AR. In company CL, C Tan is the PM, and R Chee is the QS.

The RFI was about the location and material of a staircase handrail. The handrail could not be built as shown in the original drawing, due to position conflict with the steel column footings (Figure 2). Since steel type was not specified in the original drawing, MC also wanted to clarify the type of stainless steel to be used (Type 316 or Type 304).

In the proposed Web-based system, the process is simplified through automatic notification of relevant parties as depicted in Figure 4. Liu logs in to the system, creates and submits a new RFI. Drawing of the proposed solution is uploaded and attached to the RFI. The system notifies other parties by email. Each party can easily retrieve both the proposed and original information, since it is integrated in one webpage, with hyperlinks to references. To evaluate the impact on cost, for example, Ang extracts the handrail and column items from the original quotation, puts them to deduction items, and adds new prices to additional items. The new quotation contains only but sufficient information for Tan to make the decision. The documentation of Ang's response is in Appendix I.

\section{CONCLUSIONS AND IMPLICATIONS}

This paper describes the prototyping of a system that can intelligently search for relevant information, extract useful data from the original documents, re-organize the information according to specific tasks and users, and display it in an integrated web page. The 
research demonstrates the capabilities of XML, the latest Web-based tool that enables fast data exchange in the construction project management environment.

Through a survey, the study unveils the current Web-based collaboration systems and the as-is features, their limitations and identifies additional features to be included in the proposed system. The conceptual model focuses on intelligent search and integrated presentation of Web-based information.

Prototyping the RFI case demonstrates technical feasibility of implementing the conceptual model using XML technology. It is found that the Web-based process provides the convenience of ready, complete and integrated information in a timely manner, which helps the users to make decisions faster and more accurately, so that downstream parties can take actions faster. It also helps to keep track of the collaboration process, reduce data re-inputs, and minimize errors.

This research is meaningful for Web-based project management in that it explores a new direction for information integration, i.e., intelligent search. In the near future, Webbased collaboration systems will be developed towards the platforms for automatic information exchange and integrated representation. Such a change has profound influences on both business process re-design and collaboration in the AEC industry.

The study bridges the gap between present and future development in Internet by exploring the possibility of intelligent search as one direction for the development of 
Web-based project management tool. The conceptual model is based on XML enabled metadata system. The proposed system is better than the current Web-based systems for it is able to intelligently search for relevant information, extract useful data from the original documents, re-organize the information according to specific tasks and users, and display it in an integrated web page.

The research redefines the meaning of information: Information is a set of data useful for decision-making. Not all data in a document is information for a specific user or a specific task. Therefore, it is important to filter the data in different documents and reorganize useful information to satisfy the need of a specific user or task. The research testifies that Web-based information marked up by XML can be linked to one another and speedier data exchange among Web-based documents is possible.

However, the conceptual model discussed above is not complete. It only presents use cases most relevant to the development of intelligent search and integrated presentation of Web-based information. Phases in the lifecycle of software development include requirement analysis, system design, implementation and evaluation. The research focuses mainly on requirement analysis. Study on the workflow of RFI presents a methodology for system design, but actual development of the system will involve much more than an individual's effort. Value of the conceptual model is not fully realized until the whole system is actually built and tested. 

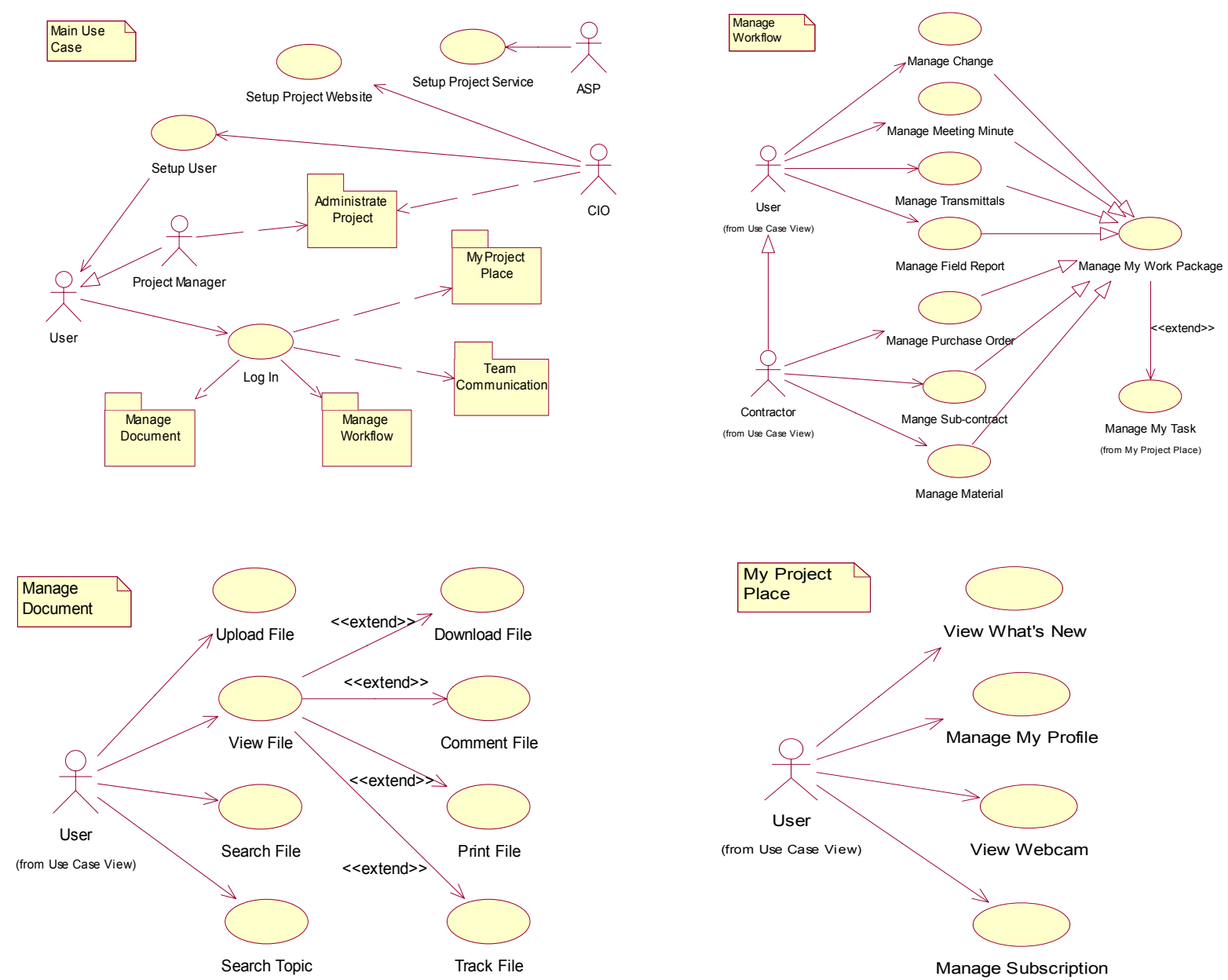

Manage Subscription

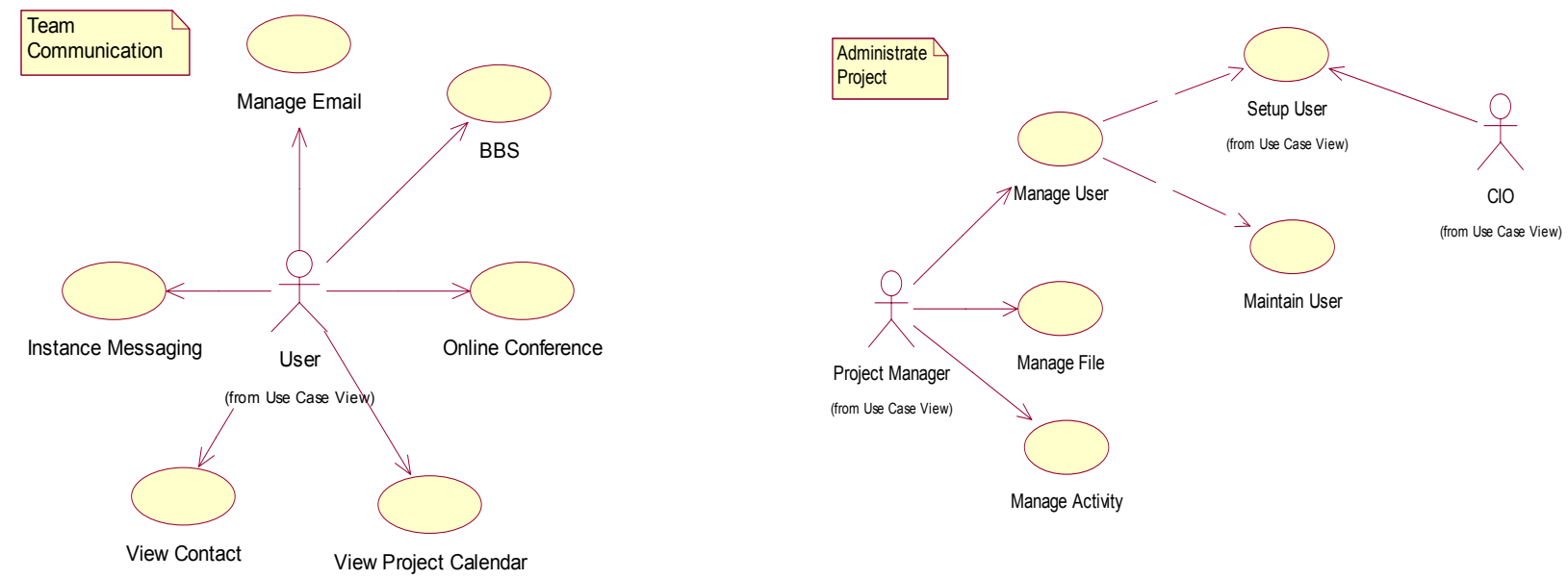

Fig 1. Schematic Diagrams Showing the Relationships among System Activities 


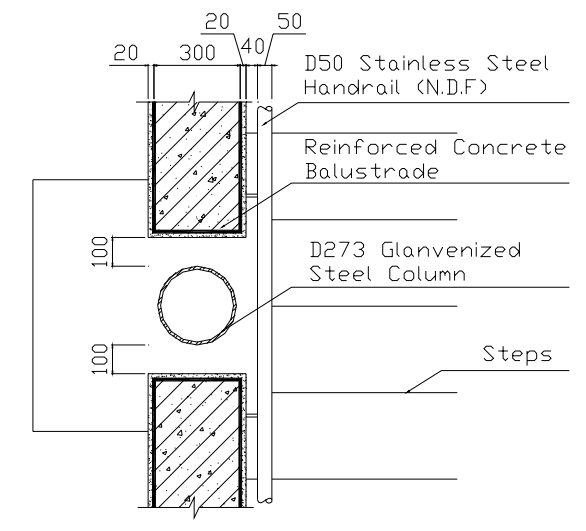

C709 TYPICAL PLAN AT GARDEN BRIDGE

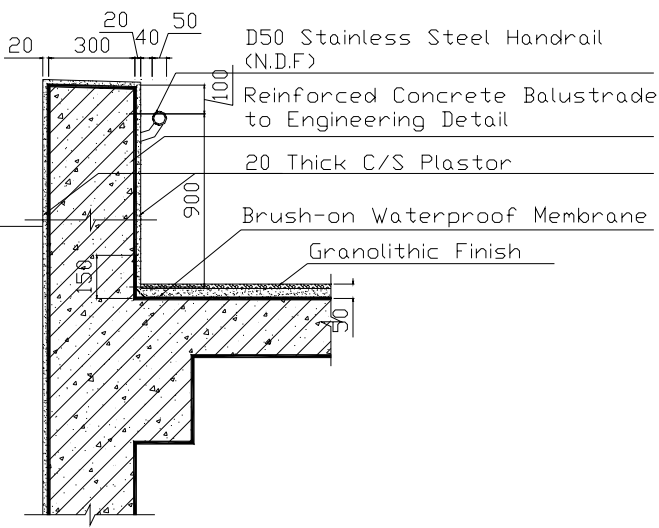

C709 TYPICAL SECTIJN AT GARDEN BRIDGE

Fig 2. Original Detail Drawings of the Parapet 


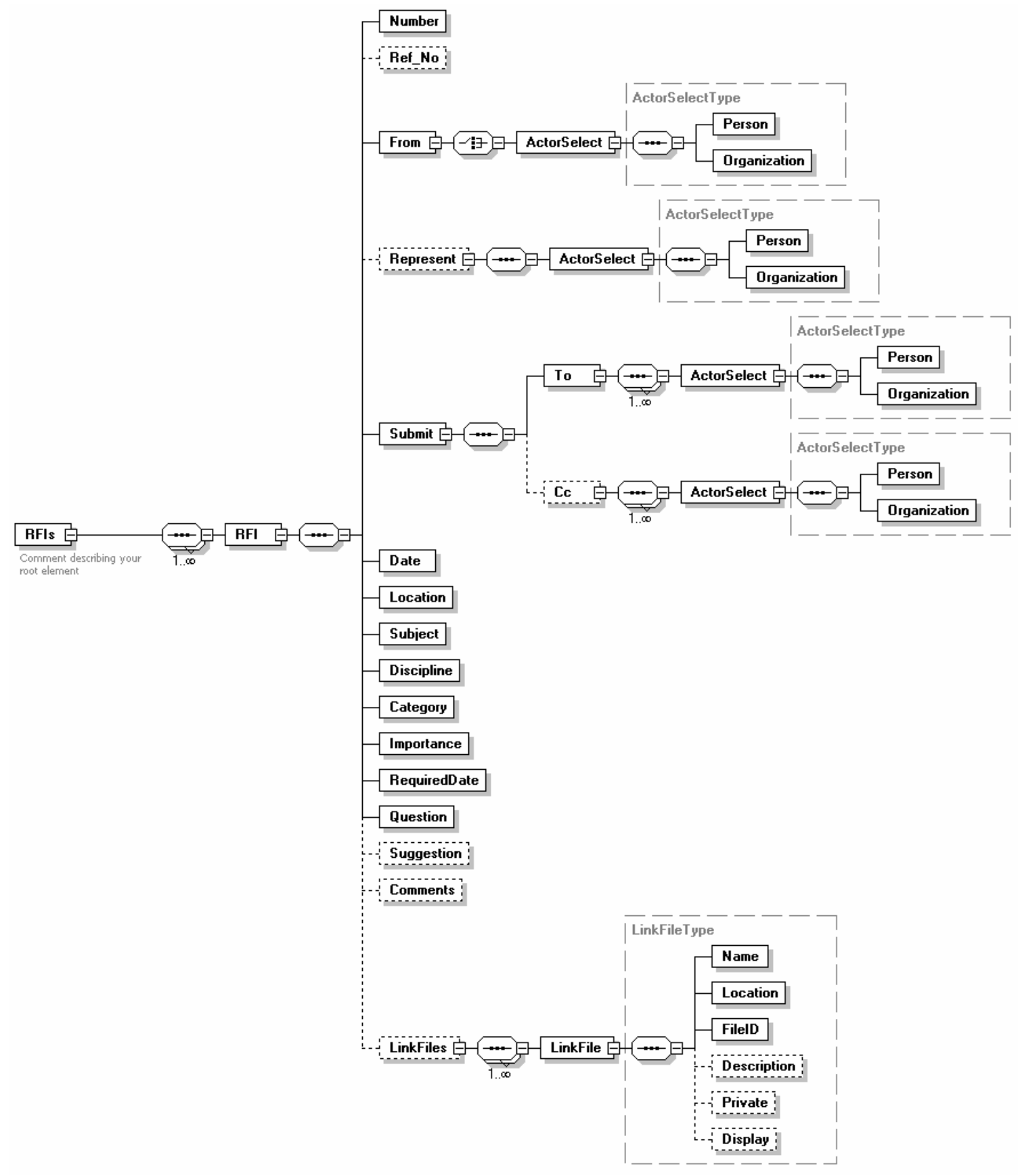

Figure 3 Elements in the RFI schema. 


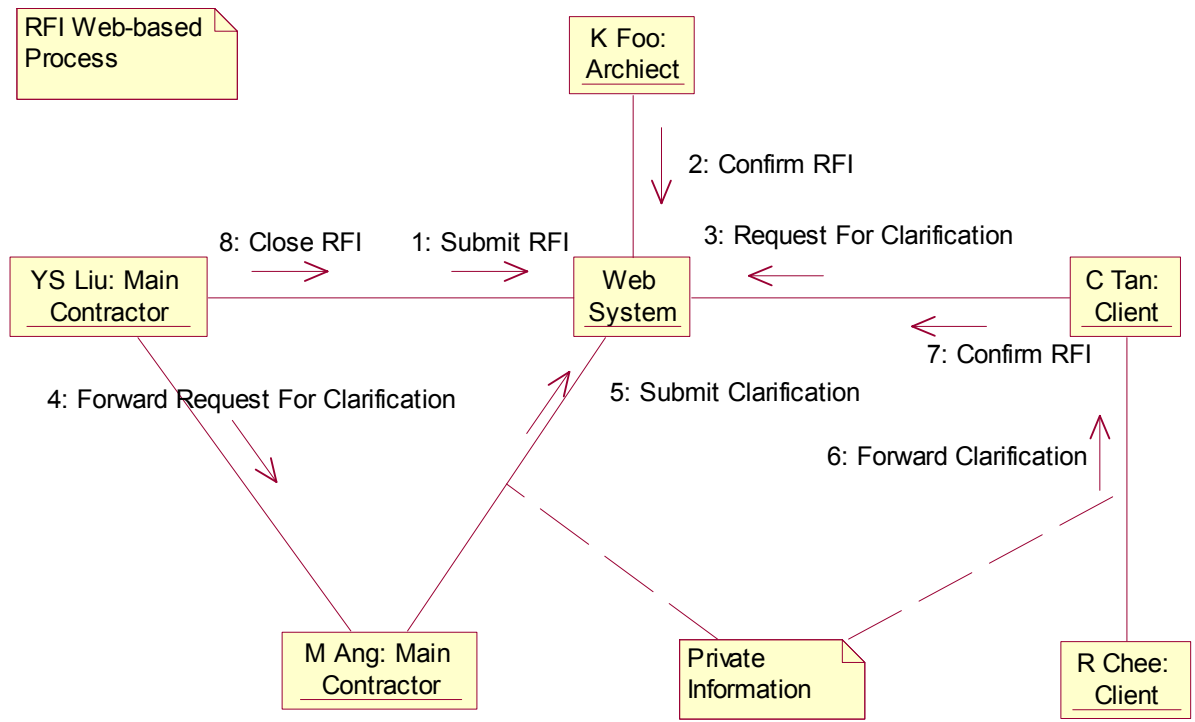

Figure 4. Collaboration Diagram of Web-based Process 
Table 1. Use Cases Involved in the Web-based RFI Process.

\begin{tabular}{|c|c|c|c|c|}
\hline & Package & Use Case & Information & Description \\
\hline 1 & & Setup User & $\begin{array}{l}\text { Information access } \\
\text { rights }\end{array}$ & $\begin{array}{l}\text { Controlling information access rights. } \\
\text { For example, K Foo has no access right } \\
\text { to the Quotation and the QFC. }\end{array}$ \\
\hline 2 & & Login & Login page & $\begin{array}{l}\text { Verifying user; retrieving user profile, } \\
\text { displaying user specific Headline page. }\end{array}$ \\
\hline 3 & My Project Place & $\begin{array}{l}\text { View What's } \\
\text { New }\end{array}$ & What's New & Providing summary of new arrival items. \\
\hline 4 & My Project Place & View My Task & Tasks & $\begin{array}{l}\text { Displaying tasks that user is responsible } \\
\text { for. }\end{array}$ \\
\hline 5 & $\begin{array}{l}\text { Manage } \\
\text { Workflow }\end{array}$ & $\begin{array}{l}\text { Manage } \\
\text { Change }\end{array}$ & $\begin{array}{l}\text { Summary of } \\
\text { Changes }\end{array}$ & Providing summary of change items. \\
\hline 6 & $\begin{array}{l}\text { Manage } \\
\text { Workflow }\end{array}$ & Manage RFI & (Response To) RFI & $\begin{array}{l}\text { Providing RFI and Response to RFI } \\
\text { forms, and the summary page when the } \\
\text { RFI is closed. }\end{array}$ \\
\hline 7 & $\begin{array}{l}\text { Manage } \\
\text { Document }\end{array}$ & Upload File & C709.dwg & $\begin{array}{l}\text { Uploading the drawing for proposed } \\
\text { solution. }\end{array}$ \\
\hline 8 & $\begin{array}{l}\text { Manage } \\
\text { Document }\end{array}$ & View File & $\begin{array}{l}\text { C709.dwg (MC v1) } \\
\text { C709.dwg (AR v1) }\end{array}$ & $\begin{array}{l}\text { Displaying files, either embedding the } \\
\text { file to the RFI, or opening it in a new } \\
\text { window, depending on how the link } \\
\text { provider wants it to display. }\end{array}$ \\
\hline 9 & $\begin{array}{l}\text { Manage } \\
\text { Document }\end{array}$ & Search Topic & $\begin{array}{l}\text { Search results of } \\
\text { handrail, integrated } \\
\text { QFC }\end{array}$ & $\begin{array}{l}\text { Providing search results of handrail, } \\
\text { integrating the selected item to the new } \\
\text { QFC. }\end{array}$ \\
\hline 10 & $\begin{array}{l}\text { Manage } \\
\text { Document }\end{array}$ & Manage Cost & Quotation, QFC & $\begin{array}{l}\text { Repositing the original Quotation and the } \\
\text { QFC. }\end{array}$ \\
\hline 11 & $\begin{array}{l}\text { Team } \\
\text { Communication }\end{array}$ & BBS & BBS & $\begin{array}{l}\text { Recording informal discussions of } \\
\text { whether the kerb can be hacked or not. }\end{array}$ \\
\hline 12 & $\begin{array}{l}\text { Administrate } \\
\text { Project }\end{array}$ & $\begin{array}{l}\text { Manage } \\
\text { Activity }\end{array}$ & Activity log & Assigning tasks to the responsible parties. \\
\hline
\end{tabular}




\section{REFERENCES}

1. Cerovsek, T., and Turk, Z. (2000). "Prototype Internet Desktop for Engineers." Product and Process Modeling in Building and Construction. Proc., 3rd European Conf. on Product and Process Modeling in the Building and Related Industries, Goncalves, Steiger-Garcao and Scherer, eds., Rotterdam, the Netherlands, 83-90. $<$ http://www.istforce.com/cgi/documents/>

2. Hannus, M., and Kazi, A.S., (2000). "Requirements for Distributed Engineering." Product and Process Modeling in Building and Construction. Proc., 3rd European Conf. on Product and Process Modeling in the Building and Related Industries, Goncalves, Steiger-Garcao and Scherer, eds., Rotterdam, the Netherlands, 41-47.

3. Howard, H.C., Levitt, R.E., Paulson, B.C., Pohl, J.G., and Tatum, C.B. (1989). "Computer Integration: Reducing Fragmentation in the AEC industry." J. Computing in Civil Engineering, .3(1), 18-32.

4. IAI. (2001). "IfcXML." [Online]. Available: $<$ http://www.iaiinternational.org/iai_international/Technical_Documents/IFCXML.htm>

5. Laintinen, J., Ollus, M., Anastasiou, M., and van den Berg, R. (2000). "Global Engineering and Manufacturing in Enterprise Networks - GLOBEMEN." Product and Process Modeling in Building and Construction. Proc., 3rd European Conf. on Product and Process Modeling in the Building and Related Industries, Goncalves, Steiger-Garcao and Scherer, eds., Rotterdam, the Netherlands, 67-72.

6. Maciaszek, L. A. (2001). Requirements analysis and system design: developing Information Systems with UML. New York, USA: Addison-Wesley. 
7. W3C (2002a). "Extensible Markup Language." $<$ http://www.w3c.org/XML/>

8. W3C (2002b). "About the World Wide Web Consortium (W3C)." $<$ http://www.w3.org/Consortium/s

9. O'Brien, M., and Al-Soufi, A. (1993). "Electronic Data Interchange and the Structure of the UK Construction Industry." Construction Management and Economics, 12(5), 457-465.

10. Tolman, F., Böhms, M., Leonard, D., and Stephens, J. (2000). "Electronic Communication in the Building and Construction Industry: What Will eConstruct Bring About?" Product and Process Modeling in Building and Construction. Proc., 3rd European Conf. on Product and Process Modeling in the Building and Related Industries, Goncalves, Steiger-Garcao and Scherer, eds., Rotterdam, 131-136.

11. Zhu, Yimin (1999). "Web-based Construction Document Processing through a Malleable Frame." Ph.D. thesis, University of Florida. UMI, Ann Arbor, USA. 


\section{APPENDIX A}

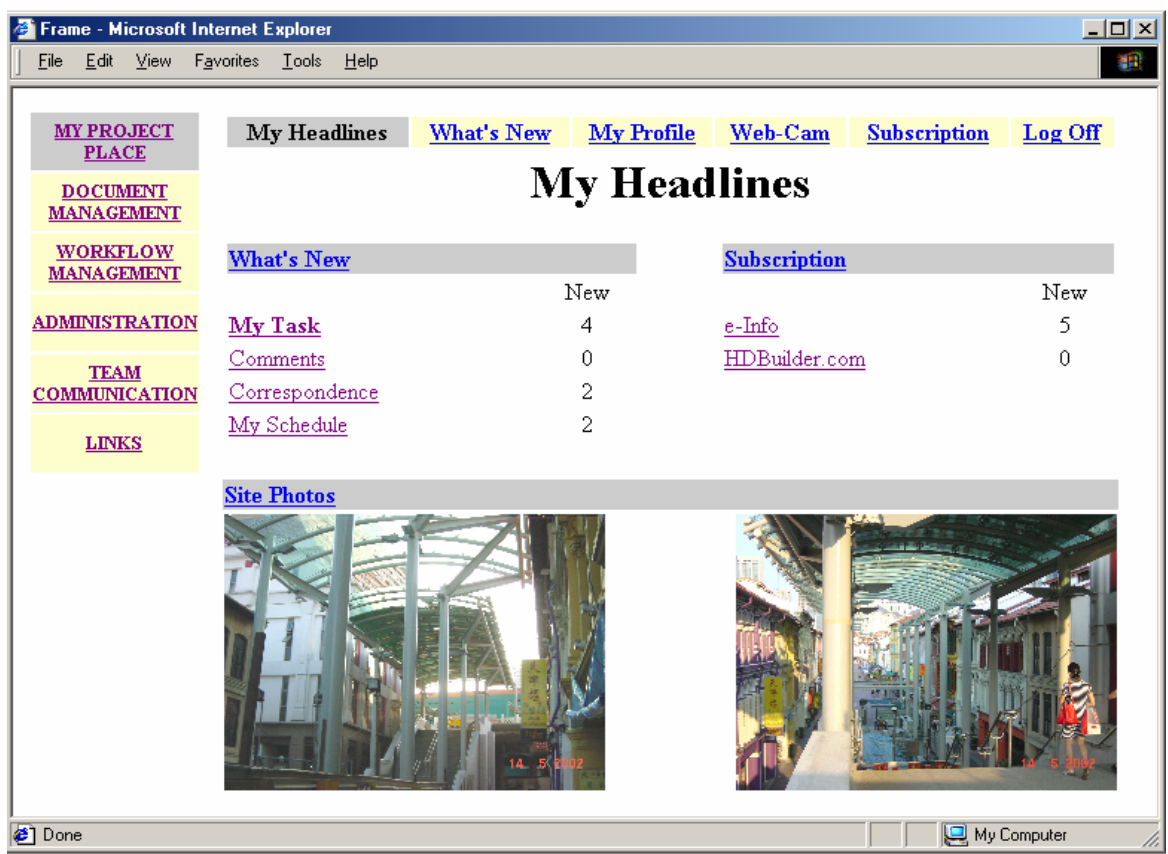

Figure A.1 M Ang's Headline Page.

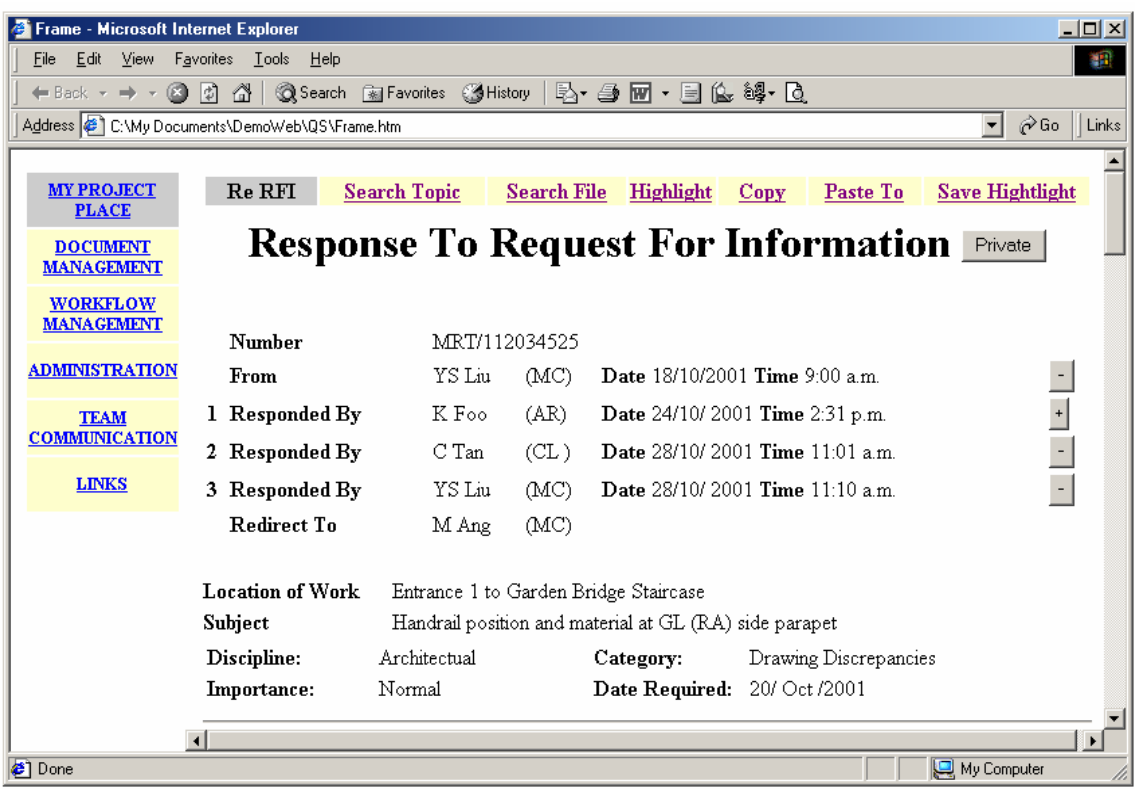

Figure A.2 M Ang's Response to Request for Information Page. 


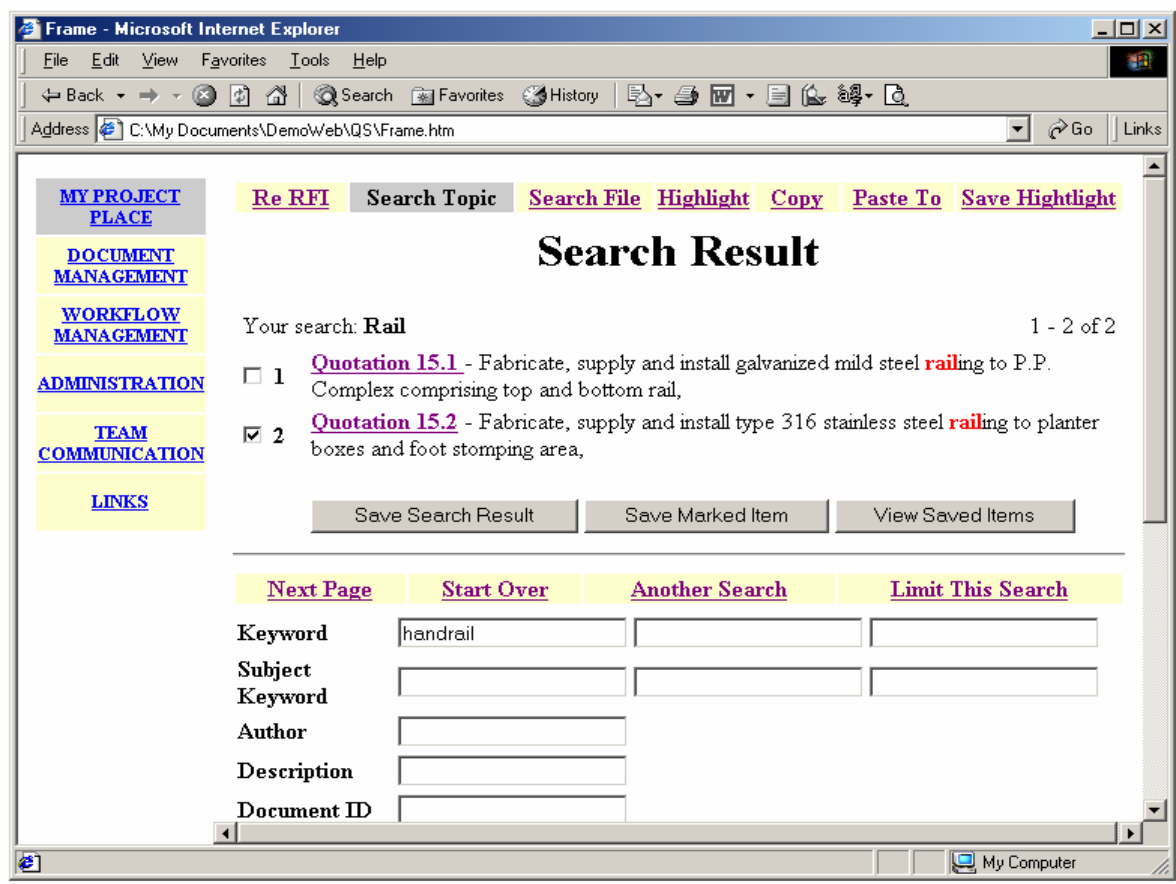

Figure A.3 M Ang's Research Result Page.

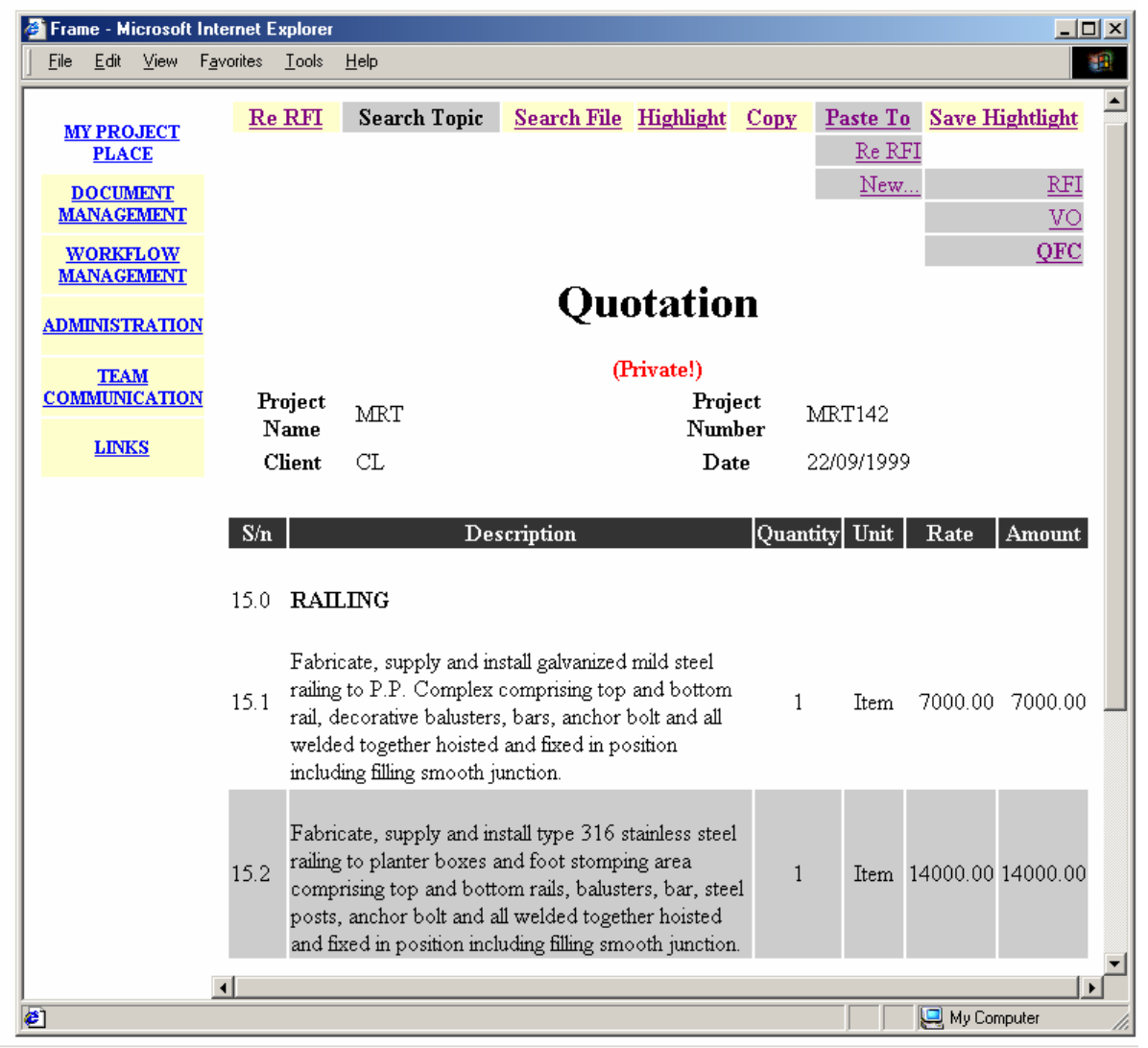

Figure A.4 M Ang's Quotation Page. 


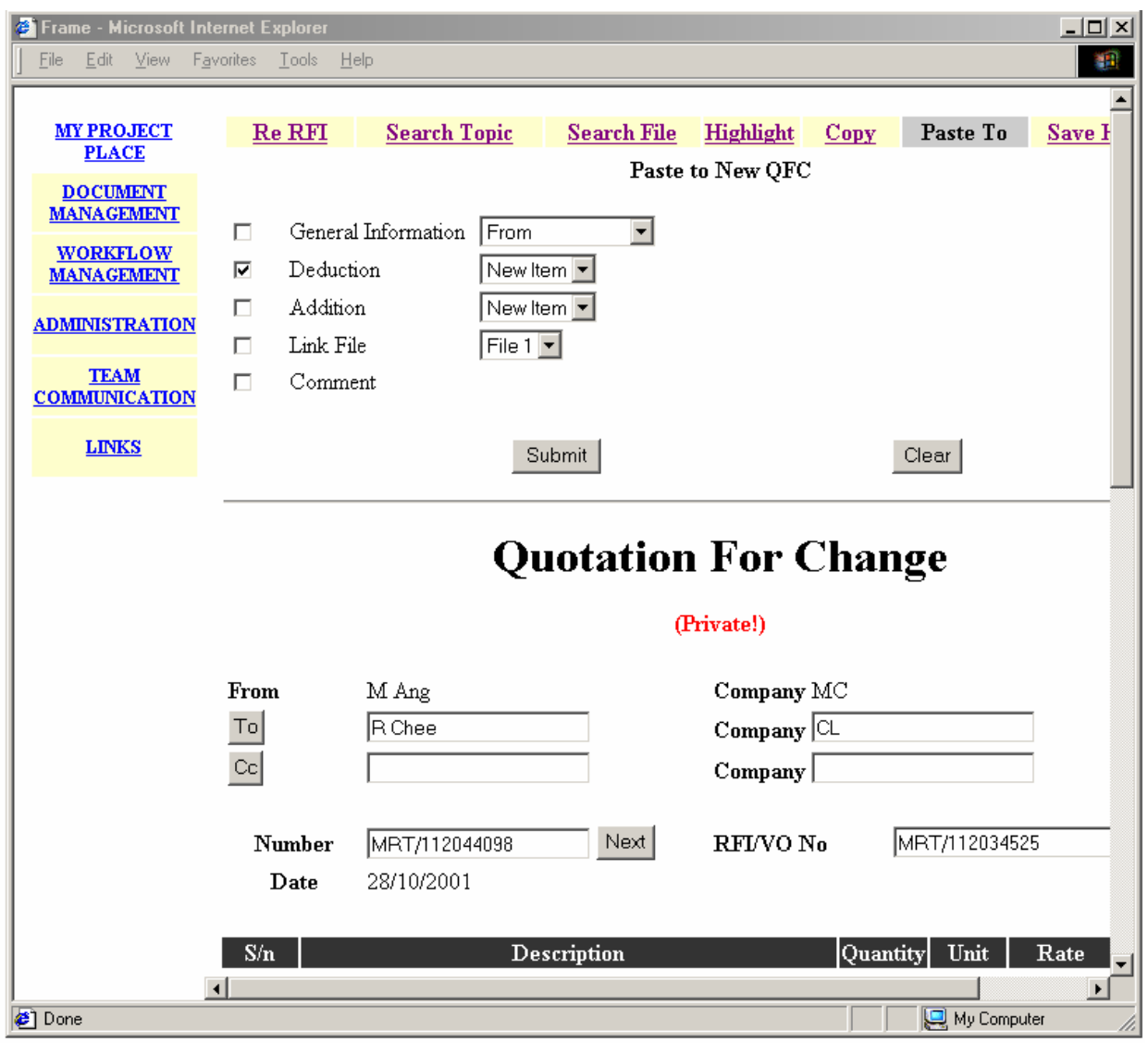

Figure A.5 M Ang's Quotation for Change Page. 


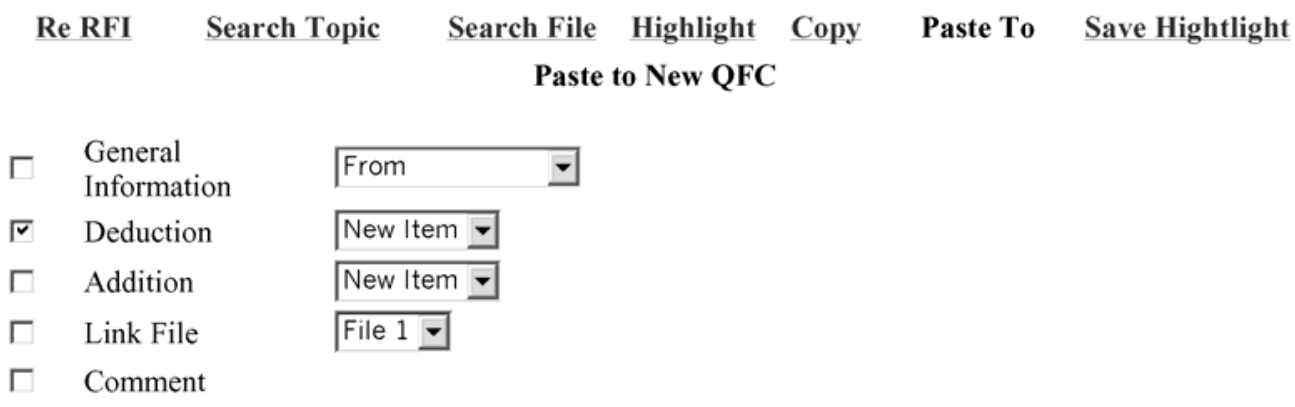

\begin{tabular}{l|l|} 
Submit & Clear \\
\hline
\end{tabular}

\section{Quotation For Change}

(Private!)

\begin{tabular}{|l|} 
From \\
To \\
\hline Cc \\
\hline
\end{tabular}

Number

M Ang

R Chee

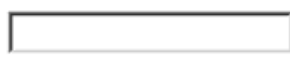

Date

\section{Next}

Company MC

Company $\mathrm{CL}$

Company

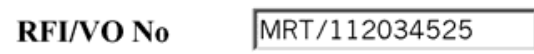

$\mathbf{S} / \mathbf{n}$

Description

Quantity Unit

Rate

Amount

1
DEDUCTION
More

Fabricate, supply and install type 316 stainless steel railing to planter boxes and foot stomping area

1.1 comprising top and bottom rails, balusters, bar, steel posts, anchor bolt and all welded together hoisted and

$1 \quad$ Item $\quad 14000.00 \quad 14000.00$ fixed in position including filling smooth junction.

2

\section{ADDITION More}

Fabricate, supply and install type 304 stainless steel railing to

2.1

planter boxes and foot stomping area comprising top and bottom rails,

balusters, bar, steel posts, anchor

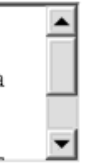

$\sqrt { 1 } \longdiv { \text { Item } } \longdiv { 8 5 0 0 . 0 0 } \longdiv { 8 5 0 0 . 0 0 }$

Figure A.6 M Ang's Quotation for Change Page (continued) 
Link Files

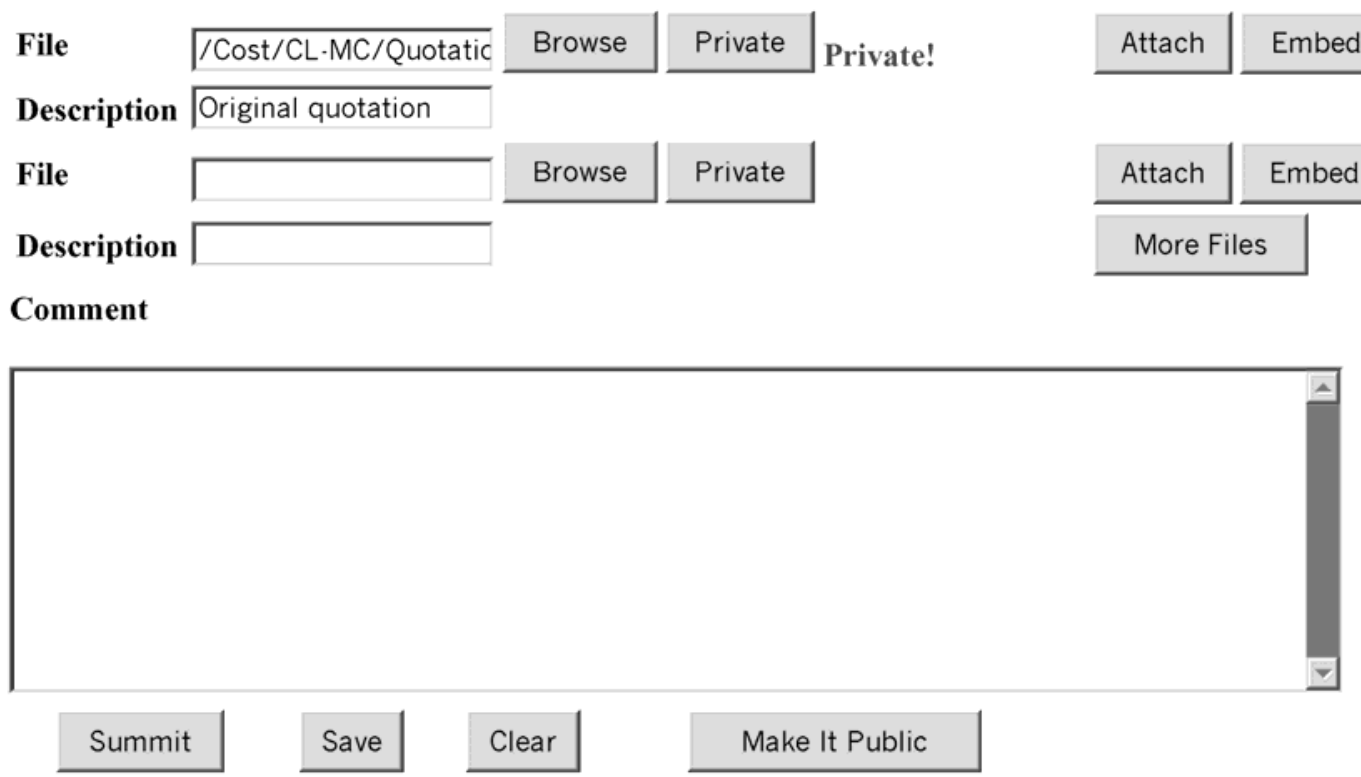

Figure A.6 M Ang's Quotation For Change Page (Continued). 


\section{Re RFI Search Topic Search File Highlight Copy Paste To Save Hightlight \\ Response To Request For Information Private}

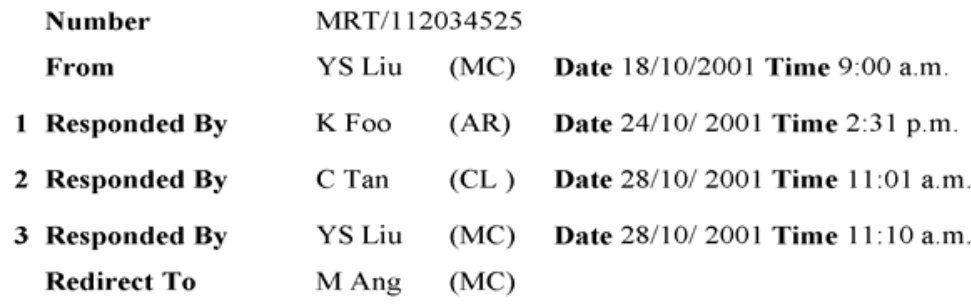

Location of Work Entrance 1 to Garden Bridge Staircase

Subject Handrail position and material at GL (RA) side parapet

Discipline: Architectual Category: Drawing Discrepancies

Importance: Normal Date Required: 20/ Oct/2001

Question Raised by YS Liu (MC) 18/10/2001 9:00 a.m. .

Question 1: Handrail position

The original design of handrail along GL(RA) is $80 \mathrm{~mm}$ away from the parapet wall. Since the position of the handrail does not coincide with the steel column footing at this position, the handrail should be at least $200 \mathrm{~mm}$ away from the parapet. Please confirm the distance.

Question 2: Handrail material

Handrail material is not specified in the original design. Please confirm whether Type 316 or Type 304 is to be used.

Suggestion

See attached drawings for handrail position.

Type 304 is recommended

Link Files

1 /drawings/shopdrawings/details/C709.dwg (MC v1) - Proposed drawing +

$2 /$ drawings/shopdrawings/details/C709.dwg (AR v1) - Original drawing +

Response By K Foo (AR) 24/10/2001 2:31 p.m. +

Response By C Tan (CL) 28/10/2001 11:01 a.m.

Answer

Question 1:

No comments, agree with AR.

Question 2:

Please provide quotation.

Response By YS Liu 28/10/2001 11:10 a.m

\section{Comment}

Question 2:

Please provide quotation to the $\mathrm{QS}$ of $\mathrm{CL}$.

Figure A.7 M Ang's Response to Request for Information Page When Submitting. 
Date $28 / 10 / 2001$

Answer Private

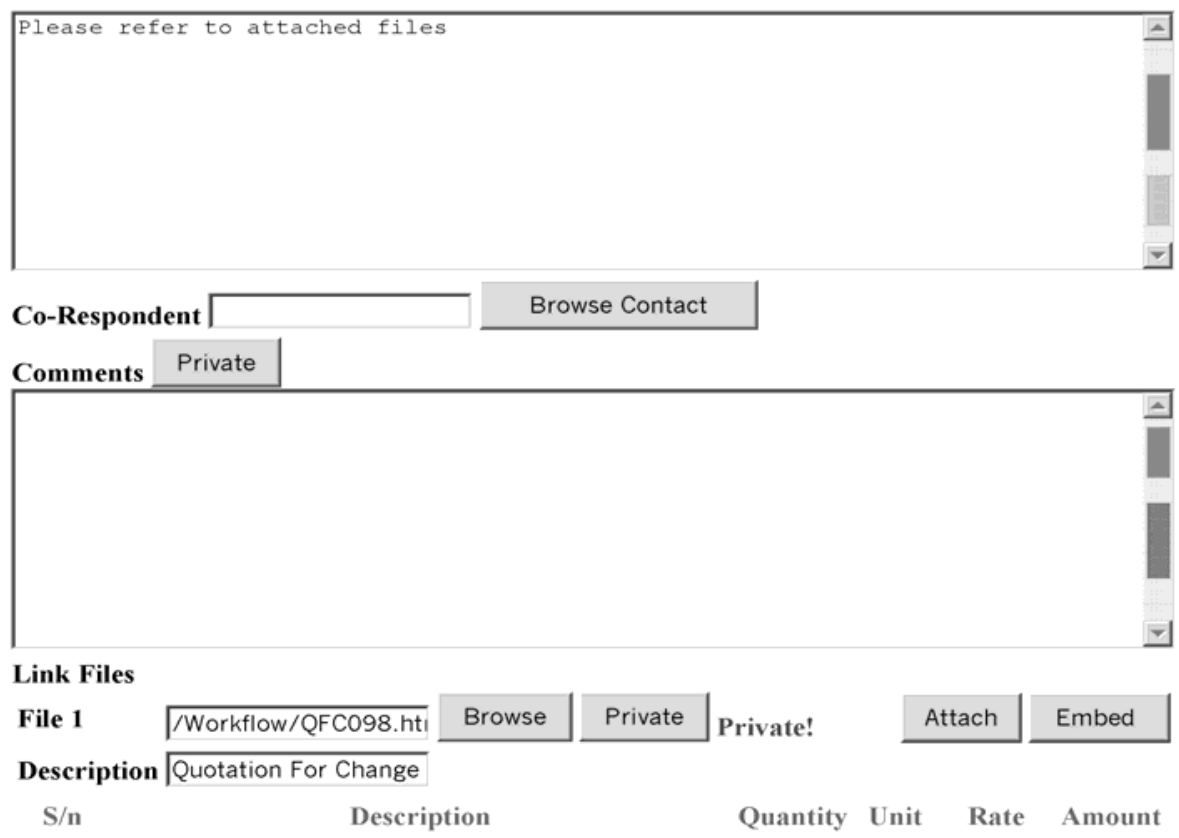

\section{DEDUCTION}

Fabricate, supply and install type 316 stainless steel railing to planter boxes and foot stomping area comprising top and bottom rails, balusters, bar, steel posts, anchor bolt and all welded together hoisted and fixed in position including filling smooth junction.

2

\section{ADDITION}

Fabricate, supply and install type 304 stainless steel railing to planter boxes and foot stomping area comprising top and bottom rails, balusters, bar, steel posts, anchor bolt and all welded together hoisted and fixed in position including filling smooth junction.

1 Item 14000.0014000 .00

\begin{tabular}{|c|c|c|c|c|}
\hline File 2 & Browse & Private & Attach & Embed \\
\hline Description & & & \multicolumn{2}{|c|}{ More Files } \\
\hline
\end{tabular}

Submit

\begin{tabular}{|c|c|c|}
\hline To & R Chee & Company \\
\hline Cc & & Company \\
\hline
\end{tabular}

Redirect

\begin{tabular}{l|l} 
& Company \\
$\mathrm{Cc}$ & Company \\
\hline
\end{tabular}

\begin{tabular}{|l|l|l|}
\hline Submit & Save & Rear \\
\hline
\end{tabular}

Figure A.7 M Ang's Response to Request for Information Page When Submitting (Continued). 